Vol. 11 (4): 919-926 (2021)

\title{
BREAST CANCER, KNOWLEDGE AND INFORMATION OF PATIENTS PRESENTED IN PRIMARY CARE, THE ROLE OF NURSING STAFF IN EARLY DIAGNOSIS
}

\author{
Zamira Imeraj $^{1 *}$, RudinaPirushi ${ }^{1}$, Denisa Veseli $(\text { Bego })^{1}$, Ilir Arifaj \\ 1"University of Medicine, Faculty of Medical Technical Sciences, Tirana, Albania; \\ Corresponding Author Zamira Imeraj, e-mail: Zamira_08@live.com;
}

Received July 2021; Accepted August 2021; Published September 2021;

DOI: $\underline{\text { https://doi.org/10.31407/ijees11.432 }}$

\begin{abstract}
Purpose: The purpose of the study is to assess the knowledge of female patients who presented to the primary care service about breast cancer, knowledge about the disease including its etiology, pathology, diagnosis and early prevention. The role of nursing staff as informants, facilitators and facilitators for early diagnosis in breast cancer prevention. Method: The study was conducted in the Tirana primary service, during the period September 2018 February 2019. The data collection tool was a self-administered questionnaire completed by 250 women who presented to the polyclinics of Tirana. The questionnaire is divided into three sections. Section A: included the socio-demographic characteristics of the participating women. Section B: assessed the family history, what knowledge and information these women had about breast cancer and who they think are the risk factors for breast cancer. Section C: researched the knowledge of these women about breast cancer prevention, self-examination, mammography and periodic checkups also collected data on the role of polyclinic nurses and the assistance they provided for early breast cancer screening. Conclusions: For the early diagnosis of breast cancer, the nursing staff in primary health care plays an important role in informing and providing appropriate data to the female population about self-examination and other procedures to detect and prevent breast cancer in a timely manner. Also informing the population through health promotion, brochures and media information regarding the early detection of cancer so that its treatment can become more successful.
\end{abstract}

Keywords: breast cancer,early diagnosis, prevention, informing, nursing role. 